Bond University

Research Repository

\title{
Load carriage
}

\section{An integrated risk management approach}

Orr, Robin M.; Pope, Rodney R.

Published in:

Journal of Strength and Conditioning Research

DOI:

10.1519/JSC.0000000000001029

\section{Licence:}

Unspecified

Link to output in Bond University research repository.

Recommended citation(APA):

Orr, R. M., \& Pope, R. R. (2015). Load carriage: An integrated risk management approach. Journal of Strength and Conditioning Research, 29, S119-S128. https://doi.org/10.1519/JSC.0000000000001029

\section{General rights}

Copyright and moral rights for the publications made accessible in the public portal are retained by the authors and/or other copyright owners and it is a condition of accessing publications that users recognise and abide by the legal requirements associated with these rights.

For more information, or if you believe that this document breaches copyright, please contact the Bond University research repository coordinator. 


\section{$3^{\text {rd }}$ ICSPP JSCR Supplement Paper}

\section{Load Carriage: An Integrated Risk Management Approach}

Brief running head: A Risk Management Approach to Load Carriage

Venue: Australian Defence Force

Robin M. Orr (Corresponding author)

Bond Institute of Health and Sport

Faculty of Health Sciences and Medicine

Bond University

Gold Coast

Queensland

Australia 4229

Ph: +61 (0) 755954448

Ph:m: +61 (0) 468646027

Email: rorr@bond.edu.au

Rodney Pope

Bond Institute of Health and Sport

Faculty of Health Sciences and Medicine

Bond University

Gold Coast

Queensland

Australia 4229

This is a non-final version of an article published in final form in Orr, R. M., \& Pope, R. R.

(2015). Load carriage: An integrated risk management approach. The Journal of Strength \&

Conditioning Research, 29, S119-S128. 
A Risk Management Approach to Load Carriage 2

$3^{\text {rd }}$ ICSPP JSCR Supplement Paper

Load Carriage: An Integrated Risk Management Approach 


\section{ABSTRACT}

Military load carriage (LC) gives rise to substantial risks to soldier health, tactical performance and mission success. The aim of this paper was to extract and synthesise the key findings of a series of LC research reports previously published by the authors. Five reviews and six studies were included, with key findings extracted and synthesised in tabulated and critical narrative form. The weight of a soldier's load is a source of risk for soldier injuries and tactical task performance. The resulting level of risk is influenced by risk modifiers (like speed of march, terrain grade and task type and duration) and risk controls (like administrative controls and physical conditioning). In the Australian context, these risk controls were limited, with soldiers carrying heavier loads than those mandated by doctrine and policy, and LC conditioning not meeting best practice. The diversity of LC contexts, combined with the influence of risk modifiers and risk controls, means that levels of risk associated with LC are not consistent and must be assessed on a case-by-case basis. Load weight and marching routes (terrains, gradients), distances, speed and duration are all potentially treatable sources of LC-related risk. Potential risk treatments include not only commanders directly addressing these specific sources of risk to the extent feasible, on a case-by-case basis, when planning or conducting LC tasks, but also improving administration controls (ie doctrine and policies) and personal protection (ie the physical conditioning of the soldier) as part of the hierarchy of controls. Practical application would involve commanders developing and implementing dedicated LC doctrine and policies and implementing and enforcing LC conditioning programs that meets best practice.

\section{KEY WORDS}

Load carriage, risk management, soldier, conditioning, military. 


\section{INTRODUCTION 2627}

Soldiers must carry military equipment and move, on foot, over various terrains for long and continuous periods. While the equipment carried is often crucial to mission success and survival, its weight is a source of risk to the soldier $(2,8,11)$. The loads imparted by stores and equipment carried by the soldier have been found to cause injury to the musculoskeletal, nervous and integumentary systems of the human body $(2,8,11)$. In addition these loads can impact on mobility, lethality and general duties performance during tactical operations $(3,9)$, thus increasing risks to the soldier of injury or death and affecting the safety and effectiveness of their team and mission (7). Of most concern, history suggests that these loads are increasing $(2,4)$. On this basis, load carriage (LC) is a notable source of risk to military soldiers and to their teams and missions.

'Risk' can be defined as the chance of something happening that will have an impact on objectives (14), with the key objective in this instance being the successful completion of an assigned mission involving LC, with a minimum of casualties and other adverse outcomes. With complex interactions of injury risks, tactical performance risks, and mission risks arising from LC, it is vital that a suitable framework to support identification, analysis and management of these risks and their interactions is routinely employed in operational decisionmaking and that such a framework provides a scaffold for rigorous and focused research that can inform this decision-making.

The Risk Management Framework (RMF) is a nationally and internationally recognised framework $(13,14)$ which allows the input, analysis, and evaluation of all relevant contextual and risk information, including that derived from research. It provides outputs which can 
inform design of treatments for identified risks in a manner commensurate with the military approach to risk management. The RMF is essentially a five-step process with two parallel processes continually feeding into these steps $(13,14)$. The RMF and its constituent steps are depicted in Figure 1.

Using the RMF as a scaffold, the aim of this focused review was to draw together and synthesise key findings from a series of reviews and studies that were recently conducted by the authors to inform risk management in operational LC. These reviews and studies $(4-9,11$, 12) investigated the context of contemporary military LC within the Australian Regular Army (ARA), risks arising from LC, and current and potential risk management strategies.

\section{METHODS}

\section{Approach to the Problem}

The current research involved critical synthesis of the findings of a series of LC reviews and studies (4-12) previously conducted and published by the authors to systematically address the steps of the RMF (Figure 1) for operational LC. The results of the reviews and studies were extracted and critically synthesised, using the RMF as a scaffold to organise the synthesis of key findings and make the findings accessible for commanders to use in each stage of the LC risk management process.

\section{Subjects}

Several of the included studies $(5,9,12)$ used selected elements of data derived from a wideranging survey of selected, currently serving Australian Army personnel from operational 
units, conducted in 2010 (9). Detailed respondent demographics as they apply to each study can be found in the parent documents $(5,9,12)$. In the studies which used selected elements of the survey data, that data was in some cases augmented by other sources of information, to provide a means of triangulation through which the validity and reliability of survey responses could be assessed. These other sources of information included injury surveillance data (11), documentation of unit training programs (5) and army doctrines and policies (5).

Ethics approval for the program of research was granted by the Australian Defence Human Research Ethics Committee (Protocol 569-09), and the Behavioural and Social Sciences Research Ethics Committee of the University of Queensland (Project number 2009001820) and all subjects were informed of the benefits and risks of the investigation prior to providing informed consent to participate in the study.

\section{Procedures}

In the first stage of the critical synthesis of the study results, key design features and findings from each of the included studies were systematically extracted and tabulated (Table 1), using the RMF as a scaffold for tabulation. The key findings were then further synthesised, using a critical narrative approach that considered risk analyses, risk prioritisation, and evidence-based risk control strategies derived from the included studies. This latter phase of the synthesis of findings from included studies identified the key learnings provided when the study findings were considered as a whole, within the structure of a modified RMF (Figure 1). 
The risk analysis technique for this program of research revolved around a risk-ranking matrix, designed to estimate the levels of severity of each identified risk through the use of consequence scales and likelihood scales. Risk prioritisation and determinations were made based on a risk tolerance threshold. Risk modifiers were drawn from the information provided in the preceding reviews and studies and were used to inform risk control measures in accordance with a hierarchy of controls (13).

\section{Statistical Analyses}

Details of the statistical approach taken for each of the studies can be found in their parent documents $(5,9,11,12)$. Across all studies, analyses were performed using SPSS v20.0 with alpha levels set at 0.05 .

\section{RESULTS}

The data sources, results and key findings of the included reviews and studies are summarised in Table 1. In this Table, each included review and study is also allocated to the step of the RMF it serves, as the first stage in the synthesis of the key findings. The findings of the included reviews and studies are further synthesised in narrative form in the Discussion section, which follows.

INSERT TABLE 1 HERE

\section{DISCUSSION}


Table 1 constitutes a quick reference guide to available research evidence regarding the LC context, risks arising from LC and existing risk controls, to inform each step in risk management for LC. Within Step 1 of the RMF (Figure 1), included reviews and studies that contributed to establishing the context of LC events (Table 1) found that increasing loads increased the energy expenditure of the carrier for any given task and alter their movement biomechanics (5). For Australian soldiers, these loads were found to be increasing across time and varied among different trades and tasks $(4,12)$. The reported loads were also commensurate with those of other allied nations $(4,12)$. Step 2 in the framework identified both injuries and reductions in tactical task performance as key risks to the carrier. In addition, current risk controls, being physical conditioning and control of LC practices through doctrines and policies, appeared to be limited (Table 1)(5). When analysed and evaluated as part of steps 3 and 4 of the RMF (Figure 1), LC was considered to be a notable source of risk to the soldier through both physical injury and reduced tactical task performance. However, the use of risk modifiers (like speed of march, gradient and terrain type) had the potential to influence the level of risk associated with a given load (5). Likewise the risk controls of physical training and policy had the potential to more strongly influence the level of risk from LC. The level of risk that would be associated with any specific LC event was therefore not consistent - as context and other factors changed or were altered, risk level also changed. Nevertheless, one consistent theme that did emerge was the primary, negative impact of load weight on the load carrier, and it should be noted that despite developments in materials and technology, soldier loads are continuing to increase over time (4).

Given the negative impact of load weight, risk treatment options to further reduce these risks to a level of risk that is 'as low as reasonably possible' are required. Risk treatment options to lower the level of risk in LC should continue to include steps to limit load weight. Additional 
risk controls (13) should also be identified or developed as a means of avoiding or reducing the impact of the identified LC risks. These risk controls may address a variety of LC factors, from personnel to equipment and environment. With a variety of risk controls potentially available, the hierarchy of controls can be used to rank the risk control methods from most to least preferred. The hierarchy of controls employed in the international RMF (13) provides six levels of risk control, being elimination, substitution, isolation, engineering controls, administrative controls and personal protective devices/measures. While listed from most preferred to least preferred treatment options, where possible a combination of multiple treatment approaches is preferred (13).

With soldiers having been consistently required to carry loads over three millennia (4), a short term solution of eliminating the soldier's load is clearly not viable. Furthermore, research identifying increases in load over time suggest that even elimination of some elements that make up the soldier's load is not a viable long term solution at this stage. In terms of substituting the load, there is no known substitution for load weight, and thus substitution does not present a workable risk control in the current military LC context at this time. It should be noted that the replacement of heavier equipment with lighter alternatives is not considered 'substitution' of the risk source, as technological or engineering interventions form the basis of the control. These types of controls are further discussed below. For the load carrying soldier, isolating the load being carried from the soldier would require separation of soldiers from their key tools of trade - tools responsible for lethality, protection and sustainment. Therefore, the use of isolation as a risk control is likewise of limited value for controlling soldier LC weights. However, considering this further, if administrative controls are effective, there is potential in some LC contexts to remove a portion of the soldiers load to a vehicle or other LC assistive device. 
When considering engineering controls, history would suggest that this is not a viable solution for controlling LC risks at the current time. Changes in the nature of warfare and technological equipment and weaponry have not reduced the solder's load over the last three millennia, but rather have continued to increase it (4). Nevertheless, some possible options in this regard are proposed later in this section. Administrative controls and personal protective devices/measures (in this case the level of physical conditioning of the soldier) appear to be the current modus operandi for LC risk treatment in the military. However, this program of research found that both of these measures were limited, with breaches in administrative controls evident in both the Australian soldier LC context and those of allied nations, and the physical conditioning of soldiers as a means of making the person more resistant to harm or degradation in tactical performance not meeting recognised best practice.

Considering the limitations surrounding the application of the hierarchy of controls to LC, three potentially viable risk treatments considered in this program of research were: (a) LC doctrine and policy implementation or revision; (b) improved LC physical conditioning; and (c) load weight reduction. While other potential risk treatments (like nutritional supplementation) may form the impetus for future research, the scope of the current program of research remained within the bounds of contemporary Australian Army practice, in order to ensure that the resulting risk treatment recommendations could be readily adopted by commanders.

Together, tailored doctrines and policies can provide a form of administrative control by reducing and controlling soldiers' exposure to risk by means of prescribing work procedures (14). However, the current program of research identified two flaws in current efforts to apply 
this risk control, being limited guidance available to inform commanders of optimal LC practices, and the available LC guidance being vague and dispersed across several doctrines. Research evidence involving U.S. soldiers in Afghanistan reported similar difficulties with load weights breaching U.S. doctrine (15). On this basis, for doctrines and policies to be an effective risk control for LC, two elements need to be addressed. First, not only do detailed and relevant LC doctrine and unit LC policies be established, as has recently been the case in the Australian Army (1), but these doctrine and policies must be enforced. Second, consideration should be given to shifting the locus of control for LC event decision-making down the chainof-command, to unit and sub-unit commanders who are at the impact point for these decisions, thus allowing operational flexibility which would still ensure practice complied with overarching guidance.

The use of LC conditioning to prepare soldiers for LC is not new (4) and has been found to be effective (2, 6). However, to be effective, conditioning protocols should match evidence based best practice. A dedicated LC training session should be conducted a minimum of once per fortnight, with loads and durations progressing up to those required in the field or on operations (6). In addition, the types of LC sessions should mimic those required in field and operational settings rather than constituting a single continuous march along a flat road (6). Units should ensure that their physical training programs are structured to meet these criteria and are a mandatory requirement for their personnel, if this risk treatment is to be effective.

The final potential risk control is that of load reduction. Soldier load weights can be reduced through two approaches, these being a permanent reduction in load weight and the temporary transfer of a portion of load weight to another LC system. A permanent reduction in load weight can be achieved through reductions in the need for soldiers to carry equipment or, more likely, 
the reduction in load weight of a given item - provided the latter is not replaced with another load item, which appears to typically be the case. A temporary transfer of load can be achieved through the use of other systems capable of carrying load or the use of an augmented LC system to transfer load away from the structure of the soldier. Key mechanisms behind these approaches to load weight reduction include both technological advances (e.g. production of lighter body armour) and changes to logistic practices (e.g. the use of vehicles to carry soldier stores). On this basis, reduction of soldier load weight, while currently not a proven viable solution, could become a risk treatment with dedicated and continuing investment.

\section{MILITARY APPLICATIONS}

LC presents as a complex source of risk, with varying influencing factors. For the commander or member charged with physically preparing soldiers for a LC task, the nature of the LC event and risk modifiers (including speed of march, terrain, duration and load placement) need to be considered alongside the load weight. Where possible, administrative controls (policy and doctrines) should provide guidance on how much load should be carried as well as ways to manage and control the interface between the soldier and the nature of the LC context. Furthermore, a dedicated LC conditioning program needs to be developed along a LC conditioning continuum, with sufficient stimulus and including one dedicated LC session per week, with loads and durations progressing to meet task requirements and the event itself commensurate with the tasks required. 


\section{REFERENCES}

1. Drain J, Orr RM, Attwells R, and Billing DC. Load Carriage Capacity of the Dismounted Combatant - A Commander's Guide. Report: DSTO-TR-2765. Victoria: Australia: Defence Science and Technology Organisation, 2012.

2. Knapik JJ, Reynolds KL, and Harman E. Soldier load carriage: historical, physiological, biomechanical, and medical aspects. Mil Med 169: 45-56, 2004.

3. Knapik JJ, Staab J, Bahrke M, Reynolds KL, Vogel JA, and O'Connor J. Soldier performance and mood states following a strenuous road march. Mil Med 156: 197200, 1991.

4. Orr R. The History of the Soldier's Load. Australian Army Journal VII: 67-88, 2010.

5. Orr R. Soldier load carriage: A risk management approach. Doctoral thesis. The University of Queensland, Australia. 2013. URL: http://espace.library.uq.edu.au/view/UQ:292953.

6. Orr R, Pope R, Johnston V, and Coyle J. Load carriage: Minimising soldier injuries through physical conditioning-A narrative review. Journal of military and veterans' health 18: 31-38, 2010.

7. Orr R, Pope R, Johnston V, and Coyle J. Load carriage and its force impact. Australian defence force journal: Journal of the Australian profession of arms 185: 52-63, 2011.

8. Orr R, Pope R, Johnston V, and Coyle J. Soldier occupational load carriage: a narrative review of associated injuries. International journal of injury control and safety promotion: 1-9, 2013.

9. Orr R, Pope R, Johnston V, and Coyle J. Soldier self-reported reductions in task performance associated with operational load carriage. Journal of Australian Strength and Conditioning 21: 39-46, 2013.

10. Orr RM, Johnston V, Coyle J, and Pope R. Load carriage and the female soldier. Journal of military and veterans' health 19: 25-34, 2011.

11. Orr RM, Johnston V, Coyle J, and Pope R. Reported Load Carriage Injuries of the Australian Army Soldier. Journal of occupational rehabilitation: 1-7, 2014.

12. Orr RM, Pope R, Coyle J, and Johnston V. Occupational Loads Carried by Australian Soldiers on Military Operations. Journal of Health Safety and the Environment 31, 2015.

13. Standards Australia Working Group MB-002-01. OHS Risk Management Handbook (HB 205-2004). Standards Australia International, 2004.

14. Standards Australia Working Group MB-002-01. Risk Management (HB 4360-2004). Standards Australia International, 2004.

15. Task Force Devil Combined Arms Assessment Team. The Modern Warrior's Combat Load. Dismounted Operations in Afghanistan April - May 2003. U.S. Army Centre for Army Lessons Learned, (2004. 


\section{FIGURE LEGENDS:}

Figure 1: The original risk management framework and the framework modified for this research program (modified from Standards Australia Working Group (13, 14)).

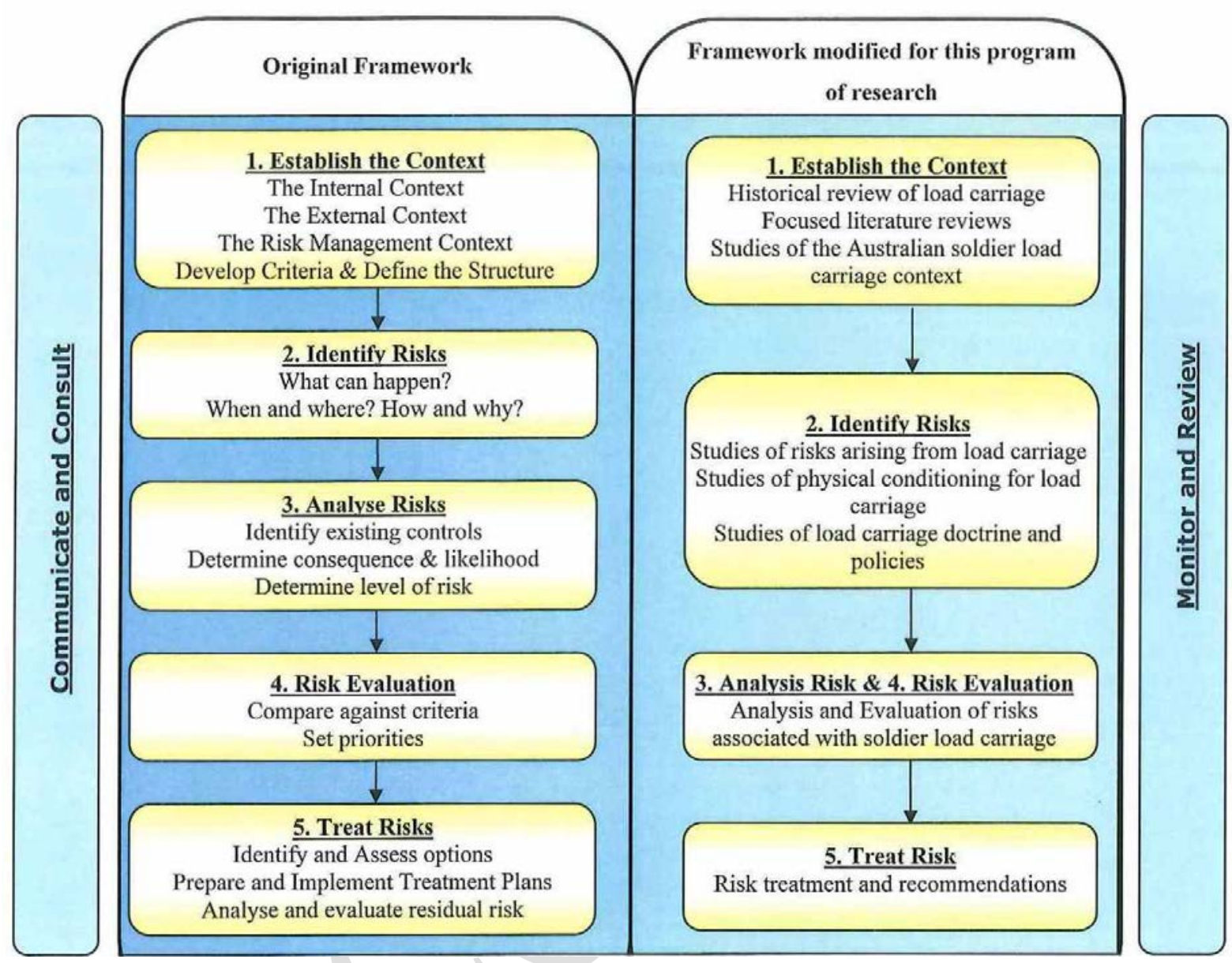


Table 1: An overview of review and study results across the program of research affiliated with their RMF step.

\begin{tabular}{|c|c|c|c|c|c|}
\hline RMF Step & $\begin{array}{l}\text { Review/ } \\
\text { Study }\end{array}$ & Data Sources & Subjects & Key Results & Key Findings \\
\hline $\begin{array}{l}\text { Establishing } \\
\text { the context }\end{array}$ & $\begin{array}{l}\text { Historical } \\
\text { review of } \\
\text { LC (4) }\end{array}$ & $\begin{array}{l}\text { Literature search; } \\
\text { historical site field } \\
\text { research. }\end{array}$ & N/A & 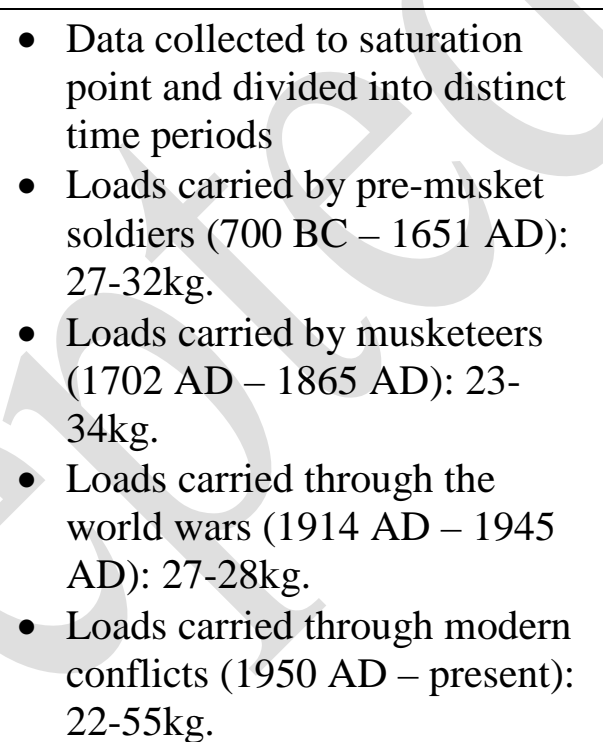 & $\begin{array}{l}\text { - } \text { Changes in the context of } \\
\text { warfare might not reduce the } \\
\text { soldier's load or requirement to } \\
\text { carry heavy loads over long } \\
\text { distances. } \\
\text { - Excessive loads can cause injury } \\
\text { and lead to loss of life. } \\
\text { - Soldiers will find a way to } \\
\text { reduce excessive loads. } \\
\text { - Absolute loads are increasing } \\
\text { - Relative (to body weight) loads } \\
\text { are similar between current } \\
\text { conflicts and those of Roman } \\
\text { Legionnaires }\end{array}$ \\
\hline
\end{tabular}




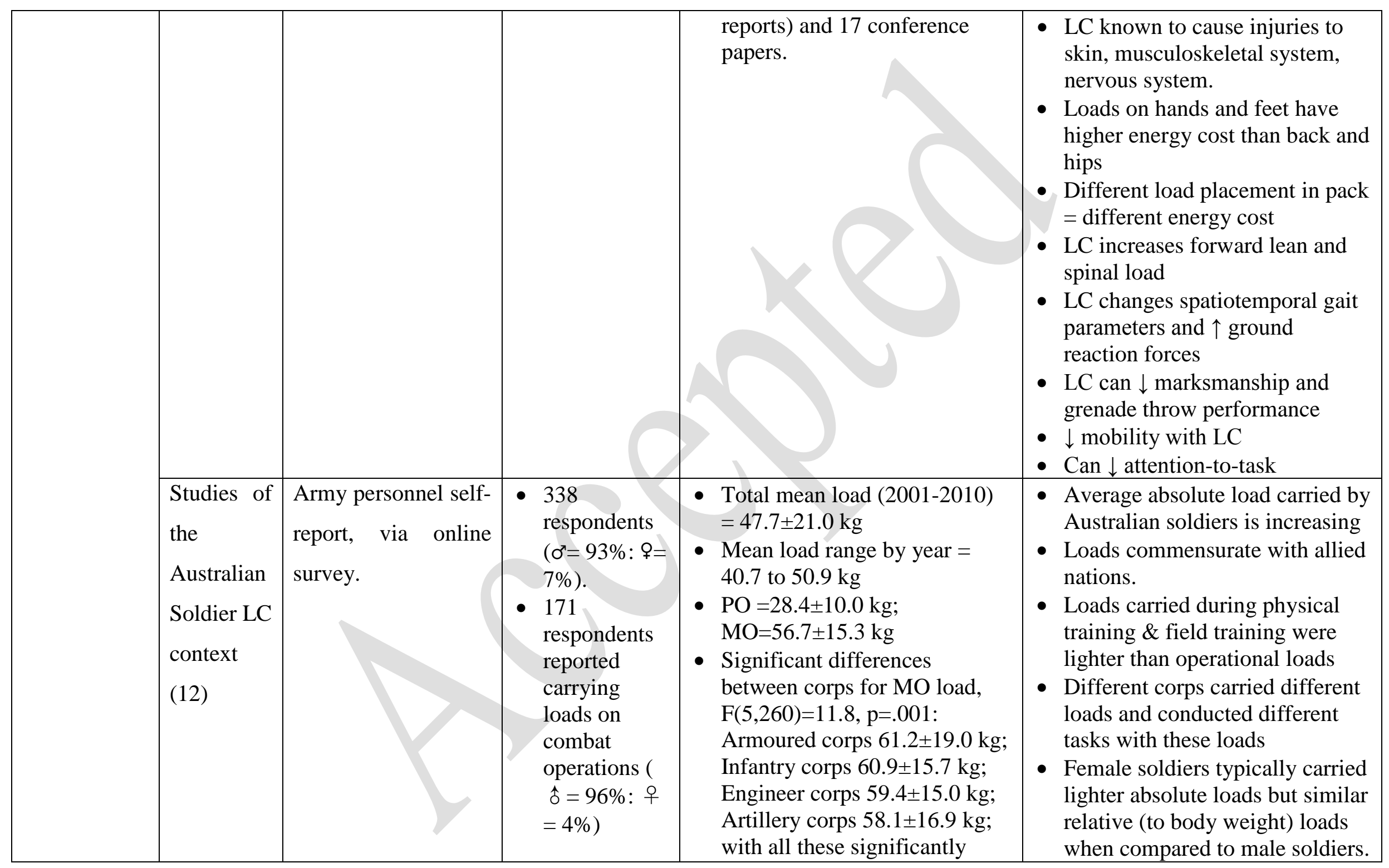




\begin{tabular}{|c|c|c|c|c|c|}
\hline & & & $\begin{array}{l}\text { - } 50 \% \text { of } 171 \\
\text { had more } \\
\text { than one } \\
\text { deployment } \\
=308 \\
\text { deployments } \\
\text { in total }\end{array}$ & 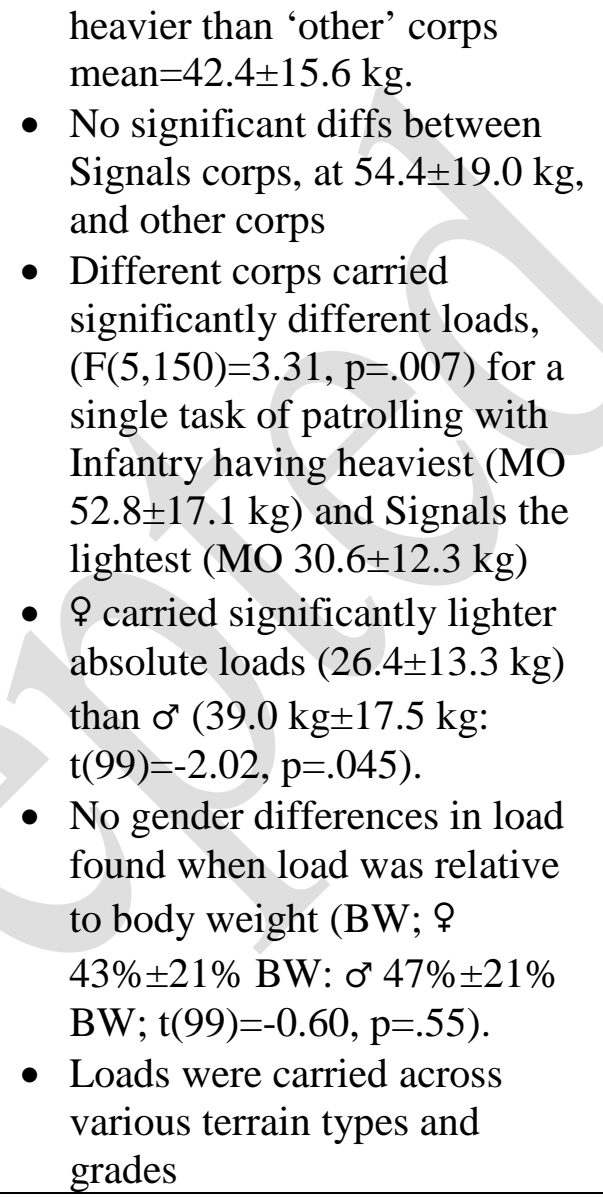 & \\
\hline $\begin{array}{l}\text { Identify } \\
\text { Risks }\end{array}$ & $\begin{array}{l}\text { Studies of } \\
\text { risks } \\
\text { arising } \\
\text { from LC } \\
\text { for the }\end{array}$ & $\begin{array}{l}\text { Army personnel self- } \\
\text { report, via online } \\
\text { survey; Defence } \\
\text { Injury surveillance } \\
\text { database (data from } 1\end{array}$ & $\begin{array}{l}\text { Self-Reported } \\
\text { Injuries \& } \\
\text { performance } \\
\text { - } 116(34 \%) \\
\text { reported } \\
\text { sustaining at } \\
\end{array}$ & $\begin{array}{l}\text { Self-reported LC injuries: } \\
\text { - } 48 \%(\mathrm{n}=56) \text { suffered a LC } \\
\text { injury during initial training } \\
\text { (32\% of these reinjured within } \\
12 \text { months; } 52 \% \text { of these } \\
\text { reinjured at some time during } \\
\text { their career). }\end{array}$ & $\begin{array}{l}\text { - LC injuries are a frequent } \\
\text { occurrence in training and } \\
\text { operational contexts } \\
\text { - Lower limbs most common site } \\
\text { of LC injuries - commensurate } \\
\text { with studies of injuries that } \\
\text { occur in a single LC task }\end{array}$ \\
\hline
\end{tabular}




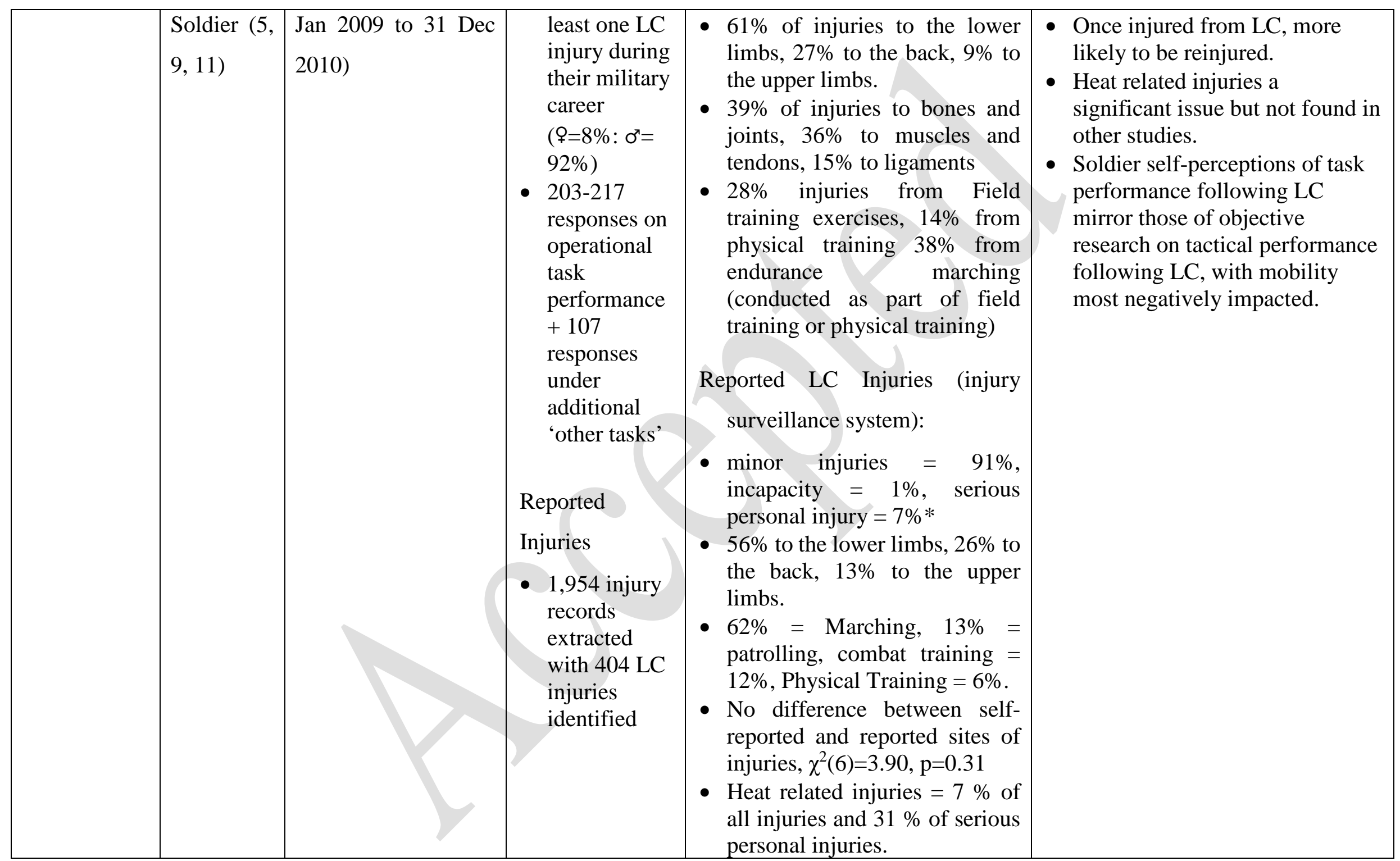




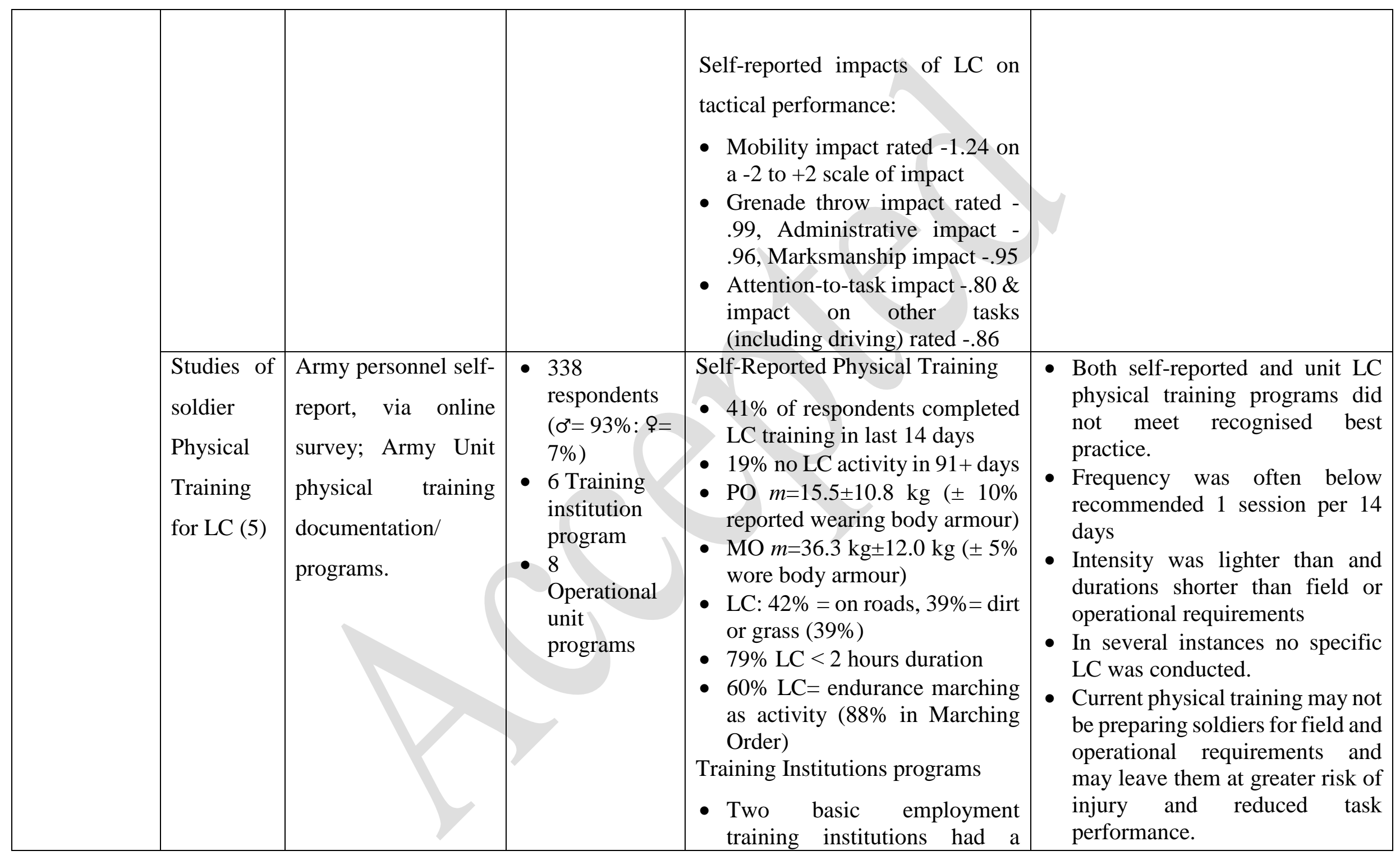




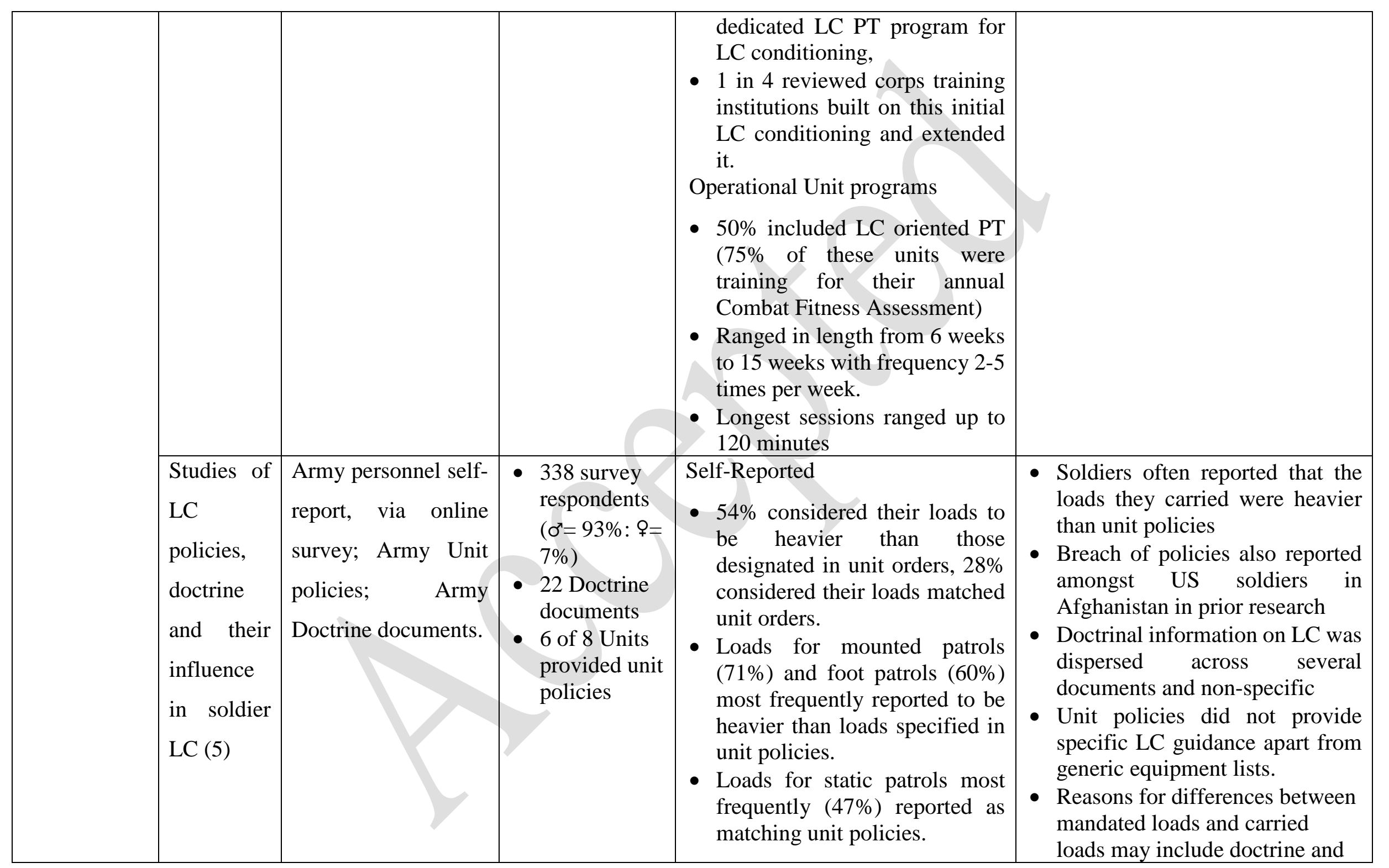




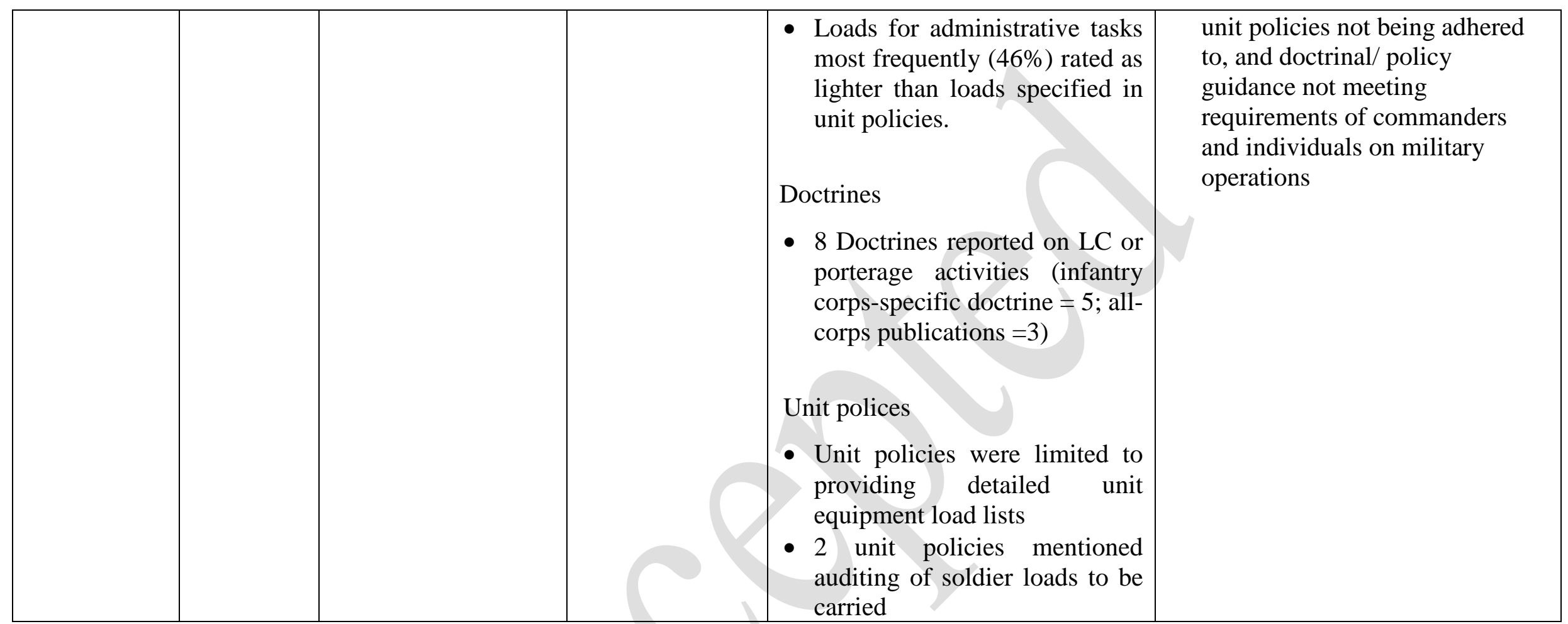

PO = Patrol Order (web belt with various pouches). $\mathrm{MO}=$ Marching Order (Patrol Order with a large backpack). BW= Body Weight.

* Does not equal $100 \%$ due to rounding. 